\title{
Empreendedorismo Feminino em Empresas de Turismo e Intenções de Crescimento dos Negócios
}

\author{
Female Entrepreneurship in Tourism Enterprises and Intentions about Businesses Growth \\ Emprendedorismo Femenino en Empresas de Turismo e Intenciones de Crecimiento de los Negocios \\ Lea Cristina Silva Bomfim \\ Universidade Federal de Sergipe (UFS), Brasil \\ leacris.bomfim@gmail.com \\ DOI: https://doi.org/10.18472/cvt.19n2.2019.1465 \\ Redalyc: http://www.redalyc.org/articulo.oa? \\ $\mathrm{id}=115460585005$
}

\author{
Rivanda Meira Teixeira \\ Universidade Federal do Paraná (UFPR), Brasil \\ rivandateixeira@gmail.com
}

Ludmilla Meyer Montenegro

Universidade Federal de Sergipe (UFS), Brasil

ludmilla2907@gmail.com

Recepção: 29 Setembro 2017

Aprovação: 29 Abril 2019

\section{Resumo:}

Apesar do reconhecimento do trabalho feminino para o setor de turismo, pouca ênfase é dedicada aos estudos sobre a mulher empreendedora nesse setor. O objetivo principal deste estudo é analisar as intenções das empreendedoras de empresas turísticas acerca do crescimento de seus negócios. Esta pesquisa é de natureza qualitativa e a estratégia adotada foi o estudo de casos múltiplos. Foram analisados cinco casos: três agências de viagem, uma pousada e um hostel. Observou-se que as empreendedoras têm a intenção de promover o crescimento dos seus negócios, porém, a forma de promovê-lo é distinta. De forma geral, percebe-se, com base nos casos analisados, que a ênfase não é apenas no retorno financeiro, mas em outros fatores, também identificados em outros estudos, como a autonomia, a qualidade de vida, o equilíbrio entre o negócio e a família. A preocupação com o impacto negativo do crescimento na família pode ser também destacada como típico de empreendedoras, além do reconhecimento da falta de preparação gerencial. Revelaram-se essas empreendedoras também cautelosas na medida em que se preocupam em administrar múltiplos papéis, além da capacidade administrativa e financeira.

PaLAVRas-ChaVE: Empreendedorismo feminino, Intenção de crescimento, Empresas turísticas.

\begin{abstract}
:
Despite the recognition of the female workforce for the tourism sector, little emphasis is placed on studies of entrepreneurial women in this sector. The main objective of this study is to analyze the intentions of female entrepreneurs in tourism enterprises about the growth of their businesses. The research is of qualitative nature and the strategy adopted was the study of multiple cases. Five cases were analyzed: three travel agencies, one lodge and one hostel. It was observed that the female entrepreneurs intend to promote the growth of their business but the way to promote it is different. In general, it is perceived, based on the analyzed cases, that the emphasis is not only on financial return, but on other factors, also identified in other studies, such as autonomy, life quality, balance between business and family. Concern about the negative impact of family growth can also be highlighted as typical of female entrepreneurs, as well as the recognition of lack of managerial preparation. These entrepreneurs have also been cautious in managing multiple roles beyond administrative and financial capacity.
\end{abstract}

KEYWORDS: Female Entrepreneurship, Growth Intentions, Tourism Enterprises.

\section{RESUMEN:}

Apesar del reconocimiento del trabajo femenino para el sector del turismo, poco énfasis es dedicado a los estudios sobre la mujer emprendedora en ese sector. El objetivo principal de este estudio es analizar las intenciones de las emprendedoras de empresas turísticas acerca del crecimiento de sus negocios. Esta investigación es de naturaleza cualitativa y la estrategia adoptada fue el estudio de casos múltiples. Se analizaron cinco casos: tres agencias de viaje, una posada y un albergue. Se observó que las emprendedoras tienen la intención de promover el crecimiento de sus negocios pero la forma de promoverlo es distinta. En general, se percibe, con base en los casos analizados, que el énfasis no es sólo en el retorno financiero, sino en otros factores, también identificados en 
otros estudios, como la autonomía, la calidad de vida, el equilibrio entre el negocio y la familia. La preocupación por el impacto negativo del crecimiento en la familia puede ser también destacado como típico de emprendedoras, además del reconocimiento de la falta de preparación gerencial. Se han revelado esas emprendedoras también cautelosas en la medida en que se preocupan en administrar múltiples papeles además de la capacidad administrativa y financiera.

Palabras ClaVE: Emprendedor femenino, Intención de crecimiento, Empresas turísticas.

\section{INTRODUÇÃO}

Os estudos sobre empreendedorismo feminino, embora relativamente recentes, já incorporaram o entendimento de que o empreendedorismo não é um fenômeno neutro em relação ao gênero (AHL; MARLOW, 2012; JENNINGS; BRUSH, 2013), que é de fundamental importância para o desenvolvimento econômico e social (ARROYO; FUENTES; JIMÉNEZ, 2016; BAUGHN; CHUA; NEUPERT, 2006; MARI; POGGESI; DE VITA, 2016), principalmente em economias emergentes (GEM, 2016).

Por outro lado, quando o tema crescimento de empresas é abordado na perspectiva de gênero, observase que, embora as evidências de que mulheres empreendedoras são menos orientadas ao crescimento do que seus homólogos masculinos (ALSOS; ISAKSEN; LJUNGGREN, 2006; BRUIN; BRUSH; WELTER, 2007; CLIFF, 1998; HASAN; ALMUBARAK, 2016), há também controvérsias, uma vez que também se evidenciam resultados opostos (ALMEIDA, 2013; WATSON; ROBB, 2012). Para Watson (2002), esses resultados podem ser explicados pelo uso de variáveis de controle inadequadas ou, de acordo com Ahl (2006), pela negligência de fatores não econômicos.

O presente estudo foi realizado no setor de turismo, reconhecidamente importante na geração de emprego e renda, sendo responsável por 9,8\% do Produto Interno Bruto mundial e por 9,5\% do total de empregos (WTTC, 2016). Por sua vez, o papel das empreendedoras nesse setor vem sendo negligenciado no campo acadêmico (ATELJEVIC; PAGE, 2011) e, apesar do reconhecimento da força de trabalho feminina para a economia, pouca ênfase é dedicada aos estudos sobre a mulher empreendedora no setor de turismo, especialmente na atividade da hospitalidade (LI, 2008).

Além do exposto, Davis e Shaver (2012) identificaram que as intenções de crescimento dos negócios diferem entre homens e mulheres a depender da fase da vida dos empreendedores, e que a família é uma variável moderadora nesse processo. Manolova, Brush e Edelman (2008) também encontraram evidências nesse sentido ao constatar que os homens que expressaram conflitos entre as suas responsabilidades empresariais e familiares, apresentaram expectativas de crescimento reduzido. Contudo, Arroyo, Fuentes e Jiménez (2016) ressaltam que, para as mulheres, o envolvimento direto da família afeta positivamente a relação entre a atitude para o crescimento e intenções de crescimento. Apesar dessas evidências, poucas pesquisas examinaram as aspirações de crescimento de empreendimentos liderados por mulheres (ZAMPETAKIS et al., 2016).

O objetivo principal deste trabalho é analisar as intenções das empreendedoras acerca do crescimento de seus negócios no setor de turismo. Especificamente, pretende caracterizar as empresas turísticas; identificar as intenções de crescimento; identificar a existência de planejamento e as estratégias de crescimento; analisar a percepção das empreendedoras sobre o impacto do crescimento do negócio sobre a família; e verificar a autoconfiança das empreendedoras quanto às suas capacidades técnicas e emocionais para promover esse crescimento. Este estudo foi realizado com empreendedoras de microempresas do setor de turismo em Aracaju, Sergipe. A seguir apresenta-se revisão sobre o empreendedorismo feminino e as intenções de crescimento de seus negócios. 


\section{EMPREENDEDORISMO FEMININO E INTENÇÕES DE CRESCIMENTO DOS NEGÓCIOS}

Estudos sobre a intenção das empreendedoras em expandir os seus negócios já são encontrados a partir da década de 1980 nos Estados Unidos. Todavia, foi na década de 1990 que Cliff (1998), ao questionar a suposição de que homens e mulheres são igualmente motivados para expandir seus negócios, concluiu que as empresas pertencentes a empreendedoras tendiam a ser menores quando comparadas às dos homens. Além disso, o autor apontou indicativos importantes para que pesquisas futuras considerassem os fatores não econômicos como, por exemplo, a decisão de manter um tamanho que possibilitasse o controle da empresa associado à possibilidade de conciliarem a vida pessoal com o trabalho. Em outras palavras, as medidas de sucesso precisavam ter significados além do financeiro para as empreendedoras (GATEWOOD; SHAVER; GARTNER, 1995).

Lindo et al. (2007) argumentam que as empresas controladas por mulheres têm obtido um tímido crescimento em função de diversas razóes. Uma delas é determinada pelo foro íntimo das gestoras, que optam por manter um crescimento lento para preservar sua autonomia, qualidade de vida e estreitos laços com seus colaboradores e clientes.

Percebe-se ainda uma dissociação do crescimento empresarial com o seu crescimento pessoal, com este último se sobrepondo ao primeiro. As empreendedoras não têm o crescimento dos negócios como um objetivo em si, mas como uma consequência de sua forma cautelosa de geri-lo (KAMAU; MCLEAN; ARDISHVILI, 1999) e buscam satisfação, realização e independência (GEBRAN; NASSIF, 2013).

Machado (2012) destaca que, enquanto a gestão masculina é orientada predominantemente para uma estratégia de crescimento rápido com foco exclusivo em resultados financeiros, as mulheres consideram outros fatores, como relacionamento social e clima organizacional. Ressaltou ainda que há entre as empreendedoras um consenso de que homens são mais agressivos no estilo de conduzir seus negócios do que mulheres, sendo essa diferença justificada em função das mulheres desempenharem outros papéis relacionados especialmente aos cuidados à família. Esse argumento é corroborado por Gomes, Guerra e Vieira (2011, p. 7), que afirmam que "as mulheres encontram dificuldades para promoverem o crescimento de suas empresas".

Vários fatores foram citados para explicar esse fato, tais como: difícil acesso ao crédito em instituições financeiras (MACHADO, 2012); difícil relacionamento com os fundos de Capital de Risco (JONATHAN, 2003; MACHADO, 2012); preconceito da sociedade (MACHADO, 2012); falta de políticas governamentais voltadas para as empreendedoras (GEDI, 2013; GEM, 2013); dificuldade de difundir as redes de relacionamentos (VASCONCELOS; SERAFIM, 2010); conflitos trabalho-família (MARI; POGGESI; DE VITA, 2016; TAKAHASHI et al., 2013) e até mesmo fatores psicológicos como o medo do fracasso (MACHADO et al., 2008; QUENTAL; WETZEL, 2002).

Robb e Watson (2012), em estudo longitudinal de cinco anos, analisaram dados de mais de 4.016 novos empreendimentos (1.041 de mulheres e 2.975 de homens) que entraram em operação nos EUA no ano de 2004. O objetivo principal foi verificar se as eventuais diferenças nos desempenhos de empresas de homens e mulheres desaparecem quando as medidas de desempenho, consideradas por esses autores, são aplicadas e as diferenças demográficas controladas. Os autores concluíram que o pressuposto de que mulheres têm dificuldade de acesso aos recursos para iniciar um empreendimento porque são discriminadas é falho, e que não existem indicações que mulheres são menos capazes do que os homens quando se trata da abertura de um empreendimento. Outro achado nessa pesquisa corrobora a teoria feminista social de que existem diferenças inerentes a homens e mulheres que refletem na maneira de gerir o empreendimento. Para sustentar tal afirmação, os autores apontam que mulheres podem optar em correr menos riscos, crescer de forma mais lenta e buscam maior equilíbrio trabalho-família, mas que essa forma de operacionalização não implica em um desempenho inferior. 
Almeida (2013) analisou o capital inicial financiamento e crescimento em termos de receita e número de empregados em 10.170 empresas turísticas criadas na Espanha desde 1996, com base em dados longitudinais para o período 1996-2006. O objetivo do estudo foi saber se o gênero é uma variável explicativa significativa. A autora constatou que empresas geridas por homens possuem mais financiamento externo, mas que esse fato não sustenta teorias de que mulheres sofrem discriminação dos bancos. Constatou-se também que as empresas do estudo geridas por mulheres mostraram um crescimento muito maior do que empresas geridas por homens em termos de vendas e criação de emprego, em particular no ramo de hotelaria.

Compreender os fatores cognitivos e contextuais que influenciam as intenções de crescimento de mulheres empreendedoras na Índia à luz da Teoria do Comportamento Planejado (TCP) foi o objetivo do estudo de Venugopal (2016). O referido autor realizou sua pesquisa em dois estágios. Inicialmente realizou estudo de casos qualitativo, seguido por pesquisa on-line com 127 mulheres empresárias para testar cinco hipóteses que relacionavam as intenções de crescimento (variável dependente) com as variáveis independentes: atitudes para o crescimento; normas subjetivas; autoeficácia empresarial percebida; e o papel das identidades familiar e ocupacional. O apoio familiar foi considerado variável moderadora entre a atitude para o crescimento e intenções de crescimento. Os resultados parecem sugerir que, além da avaliação pessoal da capacidade (autoeficácia), a atitude pessoal para o crescimento não traduz as intenções de crescimento a menos que os membros da família estejam diretamente envolvidos com a empresa. A esse suporte familiar, o autor atribui a denominação de fenômeno "paraquedas" em analogia à funcionalidade do aparato.

$\mathrm{Na}$ revisão da literatura do empreendedorismo feminino e intenções de crescimento, é possível perceber a importância da família para as empreendedoras. Mari, Poggesi e De Vita (2016) argumentam que essa abordagem ainda é subpesquisada, e investigaram como o contexto familiar afeta o desempenho desses empreendimentos. Baseado em amostra composta por 307 empreendedoras italianas foram consideradas as dimensões: motivações para começar um negócio; o apoio da família uma vez que a empresa está estabelecida; e os mecanismos para alcançar um equilíbrio adequado entre o trabalho e a vida familiar. Os resultados confirmaram a suposição de que há uma forte relação entre o desempenho das empresas com o contexto familiar das empresárias. Esse apoio exerce impactos positivos quando proporcionam o desenvolvimento de estratégias e dão suporte emocional às empreendedoras, mas também impactam negativamente, quando as empreendedoras recorrem apenas aos recursos limitados da família, desconsiderando possibilidades mais rentáveis, que poderiam acelerar o crescimento e promover inovação.

Arroyo, Fuentes e Jiménez (2016) utilizaram dados do Global Entrepreneurship Monitor (GEM) 2009 para compor amostra de 8.641 empreendedores em estágio inicial em 49 países. Propõem um modelo para explicar a expectativa de alto crescimento com base em variáveis estratégicas relevantes, abordando a identificação de possíveis diferenças de gênero nos prognosticadores dessa expectativa. Os resultados das regressões logísticas confirmaram o gênero como uma forte variável explanatória para as aspirações de crescimento, com as mulheres mostrando níveis inferiores de expectativa de alto crescimento de seus empreendimentos. Além disso, na comparação entre os determinantes da expectativa de alto crescimento por gênero, concluem esses autores que o conjunto de prognosticadores significativos não é o mesmo para homens e mulheres empreendedores. Sugeriram ainda um efeito moderador do gênero na configuração dos fatores que determinam a propensão do empreendedor para o alto crescimento. Isso pode indicar, argumentam Arroyo, Fuentes e Jiménez (2016), a necessidade de considerar as interações entre fatores pessoais, contextuais e organizacionais para melhor compreender o efeito do nível de inovação da empresa na expectativa de alto crescimento de uma perspectiva de gênero, e abrir direções para a pesquisa futura sobre as expectativas de crescimento.

No Brasil, em recente estudo, Machado, Guedes e Gazola (2017) identificaram os determinantes e dificuldades de crescimento de empresas de mulheres, bem como a relação de características da empresa e das empreendedoras com essas variáveis. A pesquisa foi realizada com uma amostra de 102 empreendedoras. Para as empreendedoras desta pesquisa, o que determina o crescimento da empresa é a quantidade de 
horas de trabalho dedicadas ao negócio, o conhecimento prévio, a capacidade de ser criativa e inovadora e a diversificação de produtos e serviços. As determinantes: horas dedicadas ao trabalho, capacidade de ser criativa e inovadora e conhecimento prévio, ressaltando que $52 \%$ das empresas foram criadas quando elas tinham menos de 30 anos de idade.

Além das dificuldades associadas ao perfil pessoal, foram identificadas por esses autores outras associadas ao perfil gerencial, como: falta de organização e de planejamento, falta de informações sobre o negócio e falta de estratégias de crescimento. Concluíram ainda que as dificuldades de crescimento não apresentaram correlação com características da empresa, ou seja, com o montante do capital inicial e também não apresentaram correlação com a característica da empreendedora, a idade com a qual criou a empresa. No entanto, o nível de escolaridade das empreendedoras apresentou correlação positiva com a falta de informações sobre o negócio. Correlação negativa foi observada entre o nível de escolaridade da empreendedora e as dificuldades: falta de planejamento e de organização da empresa, falta de equipamentos e de recursos tecnológicos e incapacidade de conciliar trabalho e família.

\section{METODOLOGIA}

Esta pesquisa é de natureza qualitativa e exploratória, pois analisa a temática ainda em consolidação, como o empreendedorismo feminino no setor de turismo. Considerando que os casos foram descritos individualmente com base em categorias previamente definidas, pode também ser classificado como um estudo descritivo. O método de pesquisa adotado foi o estudo de casos múltiplos, pois, segundo Yin (2015), essa estratégia é adequada quando se parte da premissa de que existe pouca informação sobre o tema, portanto, afirma que mais de uma empresa analisada pode trazer informaçóes complementares sobre um assunto pouco explorado.

Para estudos de casos múltiplos, não existe a preocupação com definição de universo e amostra, pois, de acordo com Yin (2015), qualquer aplicação da lógica de amostragem aos estudos de caso estaria mal direcionada, pois estes não se preocupam com a incidência dos fenômenos. Para escolha dos casos, inicialmente levou-se em consideração a recomendação de Einsenhart (1989) no que se refere à quantidade adequada para o estudo de casos múltiplos, cuja autora delimita o mínimo de quatro e o máximo de dez casos.

Foram estudadas cinco empresas de microporte do setor de turismo: três agências de viagens, uma pousada e um hostel. A escolha dos casos considerou como critério as empresas fundadas e gerenciadas por mulheres para que a sua percepção sobre o crescimento do negócio fosse relatada. Vale destacar também a adoção do critério da acessibilidade, sendo essa a razão pela qual a pesquisa contempla apenas microempresas, pois, nesses casos, as empreendedoras estão pessoalmente à frente dos negócios.

As evidências foram coletadas por meio de entrevistas pessoais semiestruturadas com as cinco empreendedoras. Além disso, foram observados documentos, como os sítios das empresas com o intuito de identificar os tipos de serviços prestados e informações gerais das empresas. As entrevistas foram gravadas e depois transcritas na íntegra. Gomes (1996) propõe a utilização de categorias específicas como forma de análise dos dados conhecidos em uma pesquisa qualitativa. Para o autor trabalhar com categorias, significa agrupar elementos, ideias ou expressões em torno de um conceito capaz de abranger tudo isso. O Quadro 1 apresenta as categorias analíticas e os elementos de análise adotados para o estudo dos casos. 


\section{QUADRO 1}

Categorias Analíticas e Elementos de Análise

\begin{tabular}{|l|l|}
\hline CATEGORIAS & ELEMENTOS \\
\hline $\begin{array}{l}\text { Características } \\
\text { dos negócios }\end{array}$ & $\begin{array}{l}\text { Ano de fundação; estrutura organizacional; estrutura física; } \\
\text { serviços prestados; quantidade de funcionários; clientes; } \\
\text { familiares na empresa. }\end{array}$ \\
\hline $\begin{array}{l}\text { Intenções de } \\
\text { Crescimento dos } \\
\text { negócios }\end{array}$ & $\begin{array}{l}\text { Intenções de crescimento no pequeno, médio e longo prazos; } \\
\text { existência de planejamento formal de crescimento e de } \\
\text { estratégias de crescimento; percepção acerca do impacto do } \\
\text { crescimento sobre a família; autocon fiança das capacidades } \\
\text { técnicas e emocionais para promover o crescimento. }\end{array}$ \\
\hline
\end{tabular}

Elaborado pelas autoras (2016)

Inicialmente foi realizada a análise e a descrição dos cinco casos individualmente com depoimentos que revelem as evidências mais relevantes das intenções de crescimento das suas empresas pelas empreendedoras. Segue-se a análise comparativa dos casos, com a técnica sugerida por Eisenhardt (1989) de cross case analysis, na qual são observadas as similaridades e as diferenças entre os casos. A forma de generalização é a analítica que, para essa autora, aperfeiçoa as definições do construto e eleva o nível da teoria. Destaca ainda essa autora, a existência de saturação teórica, quando o processo se encerra quando a possibilidade de melhorias tornase muito pequena.

\section{DESCRIÇÃO DOS CASOS}

Inicialmente, os cinco casos serão descritos individualmente. Primeiramente é apresentado o perfil das empreendedoras e, a seguir, com base nas categorias analíticas do estudo, foram descritas as características dos negócios e intenções de crescimento. Após a descrição individual, é realizada a análise comparativa dos casos.

\section{Caso Agência 1}

A empreendedora da agência 1 tem 35 anos de idade, é casada, mãe de duas filhas e natural de Aracaju. Iniciou o curso de graduação em Administração em Comércio Exterior, mas não concluiu por questões familiares. Sua experiência profissional anterior é relacionada ao setor de turismo, pois desde a adolescência trabalhou na agência de viagens de seus pais. A empreendedora não fez cursos na área gerencial, mas a experiência prática na agência da família lhe proporcionou um grande aprendizado que facilitou a criação da sua própria agência.

Ao se observar as características da agência 1, verificou-se que as atividades da empresa foram iniciadas com estrutura mínima, composta por um celular e um computador. Atualmente, possui duas lojas, com nove empregados, entre esses gerentes, mas nenhum membro da família. Utiliza atualmente sistemas de informações gerenciais que dão suporte aos processos da empresa. $O$ foco da empresa é o turismo jovem, cujo destino mais importante é a Disney. Com relação às intençóes de crescimento, a empreendedora revelou inicialmente que sua forma descentralizadora de gerenciar a empresa lhe dá flexibilidade e condições de crescimento, como explicou:

Se você for centralizador demais, a empresa não cresce. Chega um ponto que para ali porque não tem mais espaço para crescer, por isso que aqui tem as funções. Aqui mesmo o funcionário de imagem, ele vem de eventos que a gente fez ou vai fazer, ele prepara tudo e traz, e eu vou dar meu aval e pode ser aqui na empresa ou em casa.

Descreveu ainda sua metodologia de trabalho, enfatizando que conta com seus funcionários para coordenar as atividades do negócio: 
Eu tenho uma metodologia de trocas de e-mails. Aqui um e-mail de um evento que a gente faz nos Estados Unidos, é um evento médico, a gente coordena. Aqui eu tive ontem uma reunião com o funcionário, quem é o funcionário que vai coordenar isso? É um funcionário. Todas as trocas de e-mails, eu estou ali, me copia, de lá e pra cá, porque aqui eu vejo.

Atualmente a empreendedora possui uma estratégia de crescimento formalizada para expandir os negócios fora do estado, como explicou:

A gente está em fase agora de divulgação fora do estado. A gente tá montando uma rede de representantes. Em fase agora, estão Curitiba, São Paulo, Rio e interior da Bahia, mas é um processo. Como se fosse uma franquia. Que recebe uma remuneração por venda, então a gente dá todo apoio logístico, imagem, conhecimento e a pessoa batalha e vai atrás.

A empreendedora declarou ainda que se sente preparada gerencial e emocionalmente para promover o crescimento de sua empresa:

Me sinto totalmente preparada. Minha principal característica é o lado emocional; o mundo pode tá acabando e eu estou aqui equilibrada, para me tirar do sério tem que ser uma coisa bem significativa. Eu sou uma pessoa que eu mantenho um equilíbrio constante. Aqui dentro, me dou bem com todos os funcionários, mas eu sou empresa, se há alguma coisa relacionada à empresa vem funcionários aqui, a gente resolve, falam tudo que querem falar com respeito e tranquilidade.

Revelou também que criou uma sistemática para gerenciar sua empresa sem a necessidade de sua presença física e, por isso, acredita que o crescimento planejado não dificultará as relações familiares:

Hoje eu vejo isso claramente, o trabalho é para que as coisas dentro da empresa aconteçam sem a necessidade de minha presença. Hoje já é assim. Isso não quer dizer que eu não esteja dentro da empresa. Tudo o que a gente tá fazendo é para cada dia mais ter funcionários mais comprometidos, treinados, que tenham segurança na função que estão exercendo, lógico, vigiados, pra manter o mesmo padrão de qualidade, mas que as coisas aconteçam sem a necessidade de minha presença.

O Quadro 2 apresenta o resumo das categorias analíticas e elementos de análise da agência 1:

QUADRO 2

Resumo do caso agência 1

\begin{tabular}{|l|l|l|}
\hline CATEGORIAS & ELEMENTOS & RESULTADOS \\
\hline \multirow{5}{*}{ Características da empresa } & Ano de fundação & 2000 \\
\cline { 2 - 3 } & Estrutura Organizacional & 3 níveis hierárquicos \\
\cline { 2 - 3 } & Estrutura física & 1 filial \\
\cline { 2 - 3 } & Serviços prestados & Turismo internacional com foco na Disney \\
\cline { 2 - 3 } & Quantidade de funcionários & 9 funcionários \\
\cline { 2 - 3 } & Clientes & O público-alvo são jovens \\
\cline { 2 - 3 } & Familiares na empresa & Não trabalha com familiares na empresa \\
\hline \multirow{5}{*}{ Intenções de crescimento } & Intenções & Há pretensões de crescimento \\
\cline { 2 - 3 } & Estratégias pretendidas & Deseja expandir os negócios para outro estado \\
\cline { 2 - 3 } & $\begin{array}{l}\text { Percepçăo acerca do impacto do crescimento } \\
\text { sobre a família }\end{array}$ & Não impactará negativamente sobre a família pela sua estrutura gerencial \\
\cline { 2 - 3 } & Autoconfiança para promover o crescimento & Sente-se emocional e gerencialmente preparada \\
\cline { 2 - 3 } & Existência de planejamento & Sim \\
\hline
\end{tabular}

Elaborado pelas autoras (2016)

\section{Caso Agência 2}

A empreendedora da agência de viagens 2 é natural de Penedo-AL, tem 42 anos, é casada e tem três filhos. Iniciou a graduação em Administração, mas o curso não foi concluído. Aos seus 21 anos criou seu primeiro negócio, um restaurante, com o esposo. Após 18 anos fechou esse negócio para criar uma agência de viagens.

No tocante às características da agência de viagens 2, verificou-se que a data de fundação foi em 2011. Atualmente, conta apenas com a ajuda de pessoas da família, o esposo que é sócio da empresa e o filho, que está registrado como empregado. Embora a estrutura seja enxuta, sem níveis hierárquicos, há uma divisão de tarefas entre os que trabalham na empresa. Sua experiência em trabalhar com a família é positiva, e de seu relato percebe-se que essa relação lhe dá segurança e satisfação. A empreendedora atende vários públicos, mas 
seu foco está em funcionários públicos e aposentados. Os serviços prestados é basicamente a venda de pacotes turísticos, venda de seguro e locação de transportes.

No que se refere às intenções de crescimento, a empreendedora revelou que o crescimento empresarial é almejado, mas em sua visão este deve ser consoante ao crescimento pessoal e às condições financeiras da empresa, pois acredita que dessa forma evita o insucesso:

Eu espero crescer, mas eu não quero crescer rápido. Eu quero ir aprendendo aos pouquinhos e crescendo de acordo com o meu aprendizado, entendeu? Eu almejo crescer, mas não crescer de repente porque eu tenho isso comigo, que toda empresa que cresce de repente, ela pode de repente também... entendeu? Porque eu não tenho o capital pra crescer tanto, então é melhor eu ir aos pouquinhos. Então eu penso que a gente tem que ter muita cautela e muito cuidado com essa coisa de crescer para mim não ficar com muita dívida. Eu me preocupo muito com isso.

Para a empreendedora, as melhorias implementadas, ainda que pequenas, são também consideradas formas de crescimento:

Quando começou, a gente não tinha site. Aí a gente fez um face, agora já tem um site; tudo isso é crescimento. Então, meu projeto de crescer é esse. Depois pode até montar no interior uma unidade e a gente fazer mais propaganda, mas é como eu digo, tudo bem cauteloso.

Embora o crescimento empresarial seja aspirado, observou-se no relatado pela empreendedora que não existe um planejamento estratégico formalizado para se alcançar o desejado crescimento, no médio ou longo prazos, mas são realizados planos no curto prazo para prospectar clientes e incorporar novos roteiros aos pacotes turísticos da empresa:

No caso do turismo, a gente sempre bate metas. Então o meu plano é esse. Por exemplo, eu comecei fazendo Nordeste, aí eu vou e faço o Sudeste, o Sul e Centro-Oeste. Agora eu quero fazer fora do país, entendeu? Eu estou com um projeto para fazer Terra Santa, entendeu? Reunir um grupo pra Terra Santa, então os projetos da minha empresa é sempre ir para mais longe.

A empreendedora explicou ainda os procedimentos que são realizados para selecionar os clientes potencialmente aptos a realizar viagens e como define os grupos com características semelhantes. Apesar de admitir que está iniciando seu aprendizado como empreendedora, declarou que se sente gerencialmente preparada para promover o crescimento da empresa, e acredita que, se esse crescimento ocorrer de forma planejada, as relações familiares não serão afetadas:

Me sinto muito segura do que faço. Gerencialmente, me sinto. Mas eu acho que tudo, se planejando, se organizando, não chega a atrapalhar minha relação com a família não. Não acredito que chegue a atrapalhar não.

Para concluir essa descrição, o Quadro 3 apresenta o resumo das categorias analíticas e elementos de análise do caso da agência 2.

QUADRO 3

Resumo caso da agência 2

\begin{tabular}{|l|l|l|}
\hline CATEGORIAS & ELEMENTOS & RESULTADOS \\
\hline \multirow{5}{*}{$\begin{array}{l}\text { Características da } \\
\text { empresa }\end{array}$} & Ano de fundação & 2011 \\
\cline { 2 - 3 } & Estrutura Organizacional & Não posSui \\
\cline { 2 - 3 } & Estrutura física & Sem filial \\
\cline { 2 - 3 } & Serviços prestados & Pacotes turísticos nacional, seguros e locação \\
\cline { 2 - 3 } & Quantidade de funcionários & 2-Marido e filho \\
\cline { 2 - 3 } $\begin{array}{l}\text { Intenções de } \\
\text { Crescimentes }\end{array}$ & Familiares na empresa & Funcionários públicos e aposentados \\
\cline { 2 - 3 } & Intenções & Sim \\
\cline { 2 - 3 } & Estratégias pretendidas & Aumentar a carteira de clientes \\
\cline { 2 - 3 } & $\begin{array}{l}\text { Percepção do impacto do crescimento } \\
\text { sobre a familia }\end{array}$ & Impacto negativo se não contratar funcionário \\
\cline { 2 - 3 } & $\begin{array}{l}\text { Autoconfiança para promover } \\
\text { crescimento }\end{array}$ & Sente-se emocional e gerencialmente preparada \\
\cline { 2 - 3 } & Existência de planejamento & Não \\
\hline
\end{tabular}




\section{Caso Agência 3}

A empreendedora é solteira, possui 33 anos e tem uma filha. Natural de São Paulo, é graduada em Turismo e Hotelaria e pós-graduada em Habilitação Didática do Ensino Superior. A decisão de criar um negócio foi influenciada pelo pai, que é empresário. Sua decisão foi motivada também pela possibilidade de ter horários flexíveis. Aos 21 anos abriu um negócio, uma distribuidora de bebidas junto com uma avícola, que não foi bem-sucedido. Após essa experiência, iniciou outro negócio no setor de alimentação, o que lhe garantiu vasta experiência profissional antes de abrir sua agência de viagens.

$\mathrm{Na}$ caracterização da agência 3, observou-se que a empresa foi fundada em 2012 e que é gerida pela proprietária, com dois funcionários diretos e dois free-lancers. Com esses colaboradores, a agência oferece serviços diversos, como: excursões, cruzeiros, passagens de avião, viagens de grupos, viagens para casais em lua de mel, transfers e aluguel de veículos em geral e outros. Os serviços são oferecidos em função do planejamento da empreendedora, e um dos seus focos é o público jovem e recém-casados. Outro foco destacado pela empreendedora diz respeito a casais homossexuais, pois em sua visão esse é um segmento promissor.

Quanto às intenções de crescimento da empresa, a empreendedora se mostrou cautelosa quanto à forma que deseja expandir os negócios, e declarou que, no prazo de três anos, tem pretensão de abrir filial no interior do estado:

Eu quero ir devagar. Mas eu quero daqui a uns três anos estar com outra loja. Não aqui, mas no interior. Eu quero expandir para o interior. Não tenho um plano formal. Está só na cabeça por enquanto. Nem na conta bancária eu pensei ainda.

No momento, a empreendedora não se sente preparada gerencial e emocionalmente para promover o crescimento, e acredita que isso dificultará as relações familiares, como relatou:

Agora não me sinto preparada. Se fosse para agora eu teria que ter 15 funcionárias, eu acho que eu não estou preparada não. Isso ia dificultar a proximidade com a família. Eu ia abdicar mais de tempo. Isso pesa muito.

O Quadro 4 apresenta o resumo das categorias analíticas e elementos de análise do caso da agência 3.

QUADRO 4

Resumo caso agência 3

\begin{tabular}{|l|l|l|}
\hline CATEGORIAS & ELEMENTOS & RESULTADOS \\
\hline \multirow{5}{*}{ Características da empresa } & Ano de fundação & 2012 \\
\cline { 2 - 3 } & Estrutura Organizacional & 2 niveis hierárquicos \\
\cline { 2 - 3 } & Estrutura física & Sem filial \\
\cline { 2 - 3 } & Serviços prestados & $\begin{array}{l}\text { Pacotes turísticos nacional e internacional, tranfers e locação de } \\
\text { transporte }\end{array}$ \\
\cline { 2 - 3 } & & 2 funcionários \\
\cline { 2 - 3 } & Cuantidade de funcionários & Casais e grupos \\
\cline { 2 - 3 } & Familiares na empresa & Não \\
\hline Intenções de crescimento & Intenções & Crescer \\
\cline { 2 - 3 } & Estratégias pretendidas & Abrindo filial no interior do estado \\
\cline { 2 - 3 } & Percepção do impacto do crescimento sobre a familia & Impacto negativo \\
\cline { 2 - 3 } & Autoconfiança para promover o crescimento & Nẫo se sente emocional nem gerencialmente preparada \\
\cline { 2 - 3 } & Existência de planejamento & Não \\
\hline
\end{tabular}

Elaborado pelas autoras (2016)

\section{Caso Hostel}

A empreendedora tem 42 anos de idade, nasceu na cidade de São Paulo, é casada e tem uma filha. É graduada em Nutrição e participa dos cursos de aprimoramento gerencial no Sebrae para desenvolver suas habilidades 
gerenciais. A influência familiar não foi percebida pela empreendedora como relevante na sua decisão de criar seu próprio negócio. Sua experiência profissional anterior foi como nutricionista e o hostel foi o seu primeiro negócio. Aos 41 anos decidiu abdicar de sua carreira em uma empresa privada, motivada pelo desejo de conciliar suas funções como mãe e profissional.

Com relação às características do hostel, a empresa foi fundada em 2013 e, na abertura do negócio, contou com familiares e uma funcionária, logo após contratou mais dois colaboradores, assim como também aumentou a quantidade de quartos. A empreendedora informou que não tem gerente e nem possui funcionários com nível superior. Para a empresária, trabalhar com o sobrinho lhe traz segurança em razão da confiança que é depositada nesse parente. Mesmo se sentindo confortável com seu marido e sobrinho na empresa, a empreendedora evidenciou dificuldades de gerenciá-los e percebe a interferência da vida profissional e na pessoal. O negócio atende um público de várias idades que se identifica com a filosofia de hostel, a exemplo de mochileiros, mas também atende grupos de pessoas mais velhas que preferem o privativo.

Com referência às intenções de crescimento da empresa, a empreendedora explicou que há pretensões de construir mais unidades habitacionais no pavimento superior, aumentando, com isso, a capacidade do Hostel:

A gente tem ideia de daqui a mais um ano fazer a parte de cima que a gente não conseguiu fazer no início porque o dinheiro estava no final, então daqui um ano a gente tem a intenção de ampliar a parte de cima, fazer mais sete quartos.

Para atingir tal objetivo, a empreendedora explicou que possui um plano formalizado para iniciar a execução do projeto assim que todos os recursos necessários sejam reunidos:

Já tenho uma estratégia. Só falta juntar os recursos. A gente já tem um projeto da estrutura. Já tem uma noção de mais ou menos quanto a gente vai gastar. Já tem uma equipe para contratar. Então a gente já tem tudo meio programado. Só falta juntar mais um pouco.

A expansão planejada constitui um grande desafio para a empreendedora que, apesar de já possuir planos, projetos formalizados e estar constantemente desenvolvendo suas habilidades gerenciais, não se sente preparada emocional e gerencialmente para lidar com os problemas advindos desse crescimento:

Ah! Não. Nos dois, não. Emocionalmente eu acho que não. O negócio dá muito trabalho, tem muito estresse e muito problema com funcionário. E quanto mais você cresce, mais problema tem, tanto com funcionário quanto com hóspede. E gerencialmente, não. A gente está sempre aprendendo, porque não somos do ramo.

As experiências passadas com a abertura do negócio são recordadas pela empreendedora para explicar o impacto que uma carga excessiva de trabalho provocou em sua vida pessoal, e explicita que o crescimento implicará em reduzir o tempo dedicado à família:

Cada vez que vai aumentando, vai reduzindo mais o tempo com a família porque cada vez que a gente vai fazer uma coisa, vai dificultando a gente sair daqui de dentro. De início eu morava aqui dentro, agora a gente conseguiu sair, depois que a gente aumentou, a gente saiu.

Inobstante o impacto negativo do crescimento na vida familiar da empreendedora, este é perseguido, pois, em sua visão, o crescimento também possibilitará um maior afastamento do casal nas atividades operacionais do empreendimento visto que haverá a contratação de um gerente para viabilizar tal desvencilhamento:

Eu saio às $18 \mathrm{~h}$, às $16 \mathrm{~h}$, mas meu marido fica aqui até umas $11 \mathrm{~h}$ da noite. Então, quanto mais crescer, mais problemas, e mais temos que estar por perto, apesar de querer contratar alguém, um gerente que possamos sair. Mas como a gente tá no começo ainda, é muito recente ainda, então optamos por não contratar ninguém para deixar agora no início, só depois que tiver tudo mais consolidado a gente coloca alguém para ajudar.

O Quadro 5 apresenta o resumo das categorias analíticas e elementos de análise do caso do hostel. 
QUADRO 5

Resumo do caso Hostel

\begin{tabular}{|l|l|l|}
\hline CATEGORIAS & ELEMENTOS & RESULTADOS \\
\hline \multirow{5}{*}{ Características da empresa } & Ano de fundação & 2011 \\
\cline { 2 - 3 } & Estrutura organizacional & 2 niveis hierárquicos \\
\cline { 2 - 3 } & Estrutura física & 12 unidades habitacionais \\
\cline { 2 - 3 } & Serviços prestados & Hospedaria \\
\cline { 2 - 3 } & Quantidade de funcionários & 5 funcionários \\
\cline { 2 - 3 } & Clientes & Opúblico-alvo maioria lazer \\
\cline { 2 - 3 } Intenções de crescimentiares na empresa & Trabalha com familiares na empresa \\
\hline & Intenções & Crescer \\
\cline { 2 - 3 } & Estratégias pretendidas & Aumentar a quantidade de unidades habitacionais e contratar gerente. \\
\cline { 2 - 3 } & $\begin{array}{l}\text { Percepção do impacto do crescimento sobre a } \\
\text { família }\end{array}$ & Impacto negativo somente no início Impacto positivo quando contratar gerente. \\
\cline { 2 - 3 } & Autoconfiança para promover o crescimento & Não se sente emocional nem gerencialmente preparada \\
\cline { 2 - 3 } & Existência de planejamento & Sim \\
\hline
\end{tabular}

Elaborado pelas autoras (2016)

\section{Caso Pousada}

A empreendedora tem 47 anos, é natural de Salvador, é casada e tem um filho. Não concluiu o curso de graduação em Ciências Contábeis e nunca fez cursos na área gerencial. Teve influência da família para empreender, pois existem vários empreendedores na família. A pousada é o primeiro negócio da empreendedora, que decidiu interromper sua carreira como professora para criar seu próprio negócio. O seu desejo e o do marido de morar na praia foram decisivos para a abertura da pousada.

A pousada foi fundada em 2004 e fornecia hospedagem principalmente para trabalhadores do porto e da construção civil. Além disso, a empreendedora explicou que também oferece serviços de bar e restaurante. $\mathrm{Na}$ abertura do negócio, a empreendedora informou que contou com nove empregados, mas atualmente esse quantitativo foi reduzido para cinco em razão de problemas funcionais. O negócio é administrado pela empreendedora e pelo marido com ajuda do filho e do irmão. Para a empreendedora, trabalhar com familiares traz segurança, em razão da confiança que é depositada nesses parentes, mas também gera conflitos.

Com relação às intenções de crescimento, a empreendedora se sente motivada inicialmente a aumentar a quantidade de unidades habitacionais da pousada em razão das oportunidades decorrentes do setor de construção civil, como explicou:

Crescer a gente quer sempre. Há cinco, seis anos a gente pensava mais na construção desses apartamentos e agora com esse Alpha Ville e com a construção desses condomínios todos então... Primeiro eu tenho que fazer uma reforma, dá mais um serviço, eu queria contratar funcionários, mais experiente, profissional, qualificado da área mesmo. Se tiver de fazer apartamentos a gente tem condições de fazer aqui no térreo de frente para o mar, três ou quatro apartamentos.

Por enquanto, os planos para promover o crescimento do empreendimento são apenas ideias. Com relação às condições gerenciais e emocionais para promover o crescimento, a empreendedora revelou insegurança e acredita que se faz necessário mais preparo:

A gente tem que se preparar sempre. Com o que a gente recebe me sinto preparada, mas sabemos que os clientes que virão para cá serão totalmente diferentes daqueles que estamos habituados a receber. Vem mais turista, vem mais gente exigente, então a gente tem que se preparar mais. Tenho uma insegurança com relação a isso.

Além disso, a empreendedora acredita que, mesmo trabalhando com a família, os desafios advindos desse almejado crescimento poderão dificultar as relações familiares:

Acho que esse crescimento vai dificultar a minha relação com a família, mas tá todo mundo aqui trabalhando.

O Quadro 6 apresenta o resumo das categorias analíticas e elementos de análise do caso Pousada: 
QUADRO 6

Resumo do caso Pousada

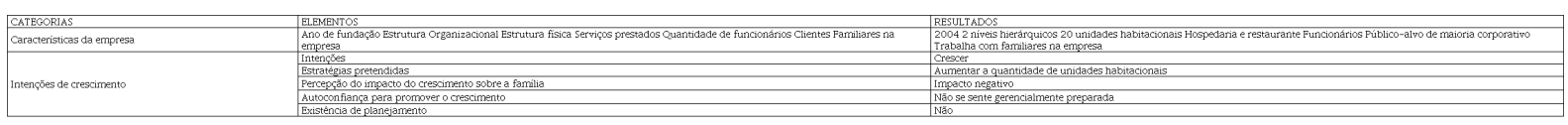

Elaborado pelas autoras (2016)

\section{ANÁLISE COMPARATIVA DOS CASOS}

As agências que participaram desta pesquisa foram criadas recentemente, pois apenas uma delas foi iniciada no ano 2000, há 14 anos. Quando se compara esses dados com a classificação adotada pelo GEM (2015), no qual são considerados empreendimentos iniciais os criados em até 3,5 anos e estabelecidos os que têm mais de 3,5 anos, observou-se que a Agência 1 é uma empresa estabelecida, enquanto que as Agências 2 e 3 são empreendimentos iniciais. Por sua vez, o Hostel é empresa nascente e a Pousada é empresa estabelecida, com aproximadamente 10 anos de existência.

Com relação ao número de empregados, adotou-se o critério do Instituto Brasileiro de Geografia e Estatística (IBGE), utilizado pelo Serviço Brasileiro de Apoio às Micro e Pequenas Empresas (SEBRAE, 2013), em que empresas no setor de serviços são consideradas micro se possuírem até nove empregados. No tocante à estrutura organizacional, observou-se que a Agência 1 foi a única que apresentou estrutura organizacional com até três níveis hierárquicos e os demais têm apenas até dois níveis. Nessa Agência 1, gerentes foram contratados para auxiliar nas funções administrativas. Com relação à estrutura física, um empreendimento iniciou com número de unidades habitacionais inferior e aumentou depois, enquanto que outro manteve o mesmo quantitativo. O Hostel, na abertura, possuía seis unidades e atualmente o empreendimento contempla 14, existindo ainda planos para expansão. Teixeira (2005), em pesquisa realizada no setor hoteleiro de Sergipe, também verificou que esses estabelecimentos possuíam uma estrutura organizacional simples, com no máximo três níveis hierárquicos, sendo que $63,3 \%$ correspondem à parcela composta por dois níveis e $36,6 \%$ com três níveis.

Em se tratando dos serviços oferecidos e o público-alvo, as empreendedoras das agências demonstraram conhecimento do mercado, pois a maioria atua em nichos no setor turístico alinhando o perfil dos clientes com a oferta de serviços. A especialidade da Agência 1 é viagens internacionais de grupos de jovens, principalmente para a Disney; a Agência 2 atua com o turismo de terceira idade e de funcionários públicos em âmbito nacional; a Agência 3 foca em grupos como formandos e casais jovens. Os serviços oferecidos pelos meios de hospedagem atendem um público que procura lazer a um custo reduzido. A Pousada possui 20 quartos e atende em sua maioria profissionais da construção civil que trabalham na região. Oferece ainda serviços de restaurante para os todos os públicos.

No que se refere à participação de familiares nas atividades das agências, apenas três empreendedoras destacaram que parentes também são colaboradores. $\mathrm{Na}$ pousada e no hostel, as empreendedoras administram o empreendimento também com a ajuda de parentes. Todas destacaram como fatores positivos a confiança e a segurança que se engendra desses relacionamentos; como aspecto negativo, destacaram os problemas advindos da não delimitação da vida pessoal e profissional. Teixeira e Morrison (2004) constataram que em $93,3 \%$ dos empreendimentos hoteleiros sergipanos pesquisados existem pessoas da família trabalhando nas diversas atividades, em geral, o cônjuge, filhos, irmãos e sobrinhos. Em todos os casos, podem ser destacados como fatores positivos a confiança e a segurança que se engendra desses relacionamentos, o que denota o impacto positivo do suporte emocional da família às empreendedoras, como observado nos estudos de Mari, Poggesi e De Vita (2016) e Venugopal (2016). 
Outra característica em comum entre os empreendimentos hoteleiros diz respeito ao papel do cônjuge. $\mathrm{Na}$ Pousada, o marido é sócio e exerce influência nas decisões. No caso do Hostel, apesar de o marido não ter participação formal em sociedade, recebe o status de parceiro pelo grau de envolvimento e colaboração no negócio. Esse resultado converge parcialmente para o estudo de Teixeira e Morrison (2004), no qual se observou que os principais sócios dos negócios hoteleiros de pequeno porte em Sergipe não eram apenas esposos(as), mas também pai/mãe, irmão(ã) e filhos(as).

Observou-se que o crescimento do negócio é almejado pelas empresárias, porém, a forma de promovê-lo difere entre elas. A empreendedora da Agência 2 pretende desenvolver internamente sua empresa e aumentar a carteira de clientes, e as Agências 1 e 3 pretendem expandir o negócio em outros mercados abrindo filiais. Para as empresas hoteleiras, o crescimento está associado ao aumento das unidades habitacionais.

Em todos os casos, o retorno financeiro não foi associado ao crescimento. Esse fato chama atenção por convergir para outros estudiosos no sentido de entender que as percepções do crescimento vão além do aspecto financeiro (GATEWOOD; SHAVER; GARTNER, 1995; MACHADO, 2012) e que isso é apenas uma consequência de suas ações (KAMAU; MCLEAN; ARDISHVILI, 1999). Atitudes como as descritas anteriormente já foram constatadas por Cliff (1998) que considera ser essa uma das razões que limitam o crescimento de empresas criadas por mulheres e também uma justificativa para explicar o porquê dessas empresas serem menores que empresas criadas por homens. Já Lindo et al. (2007) comentam que o crescimento ocorre, mas de forma lenta preservando-se a autonomia e a qualidade de vida das empresárias.

Analisando-se a percepção das empreendedoras acerca do impacto do crescimento sobre a família, observou-se que apenas as Agências 1 e 2 declaram estar preparadas emocional e gerencialmente para promoverem o crescimento de suas empresas sem que comprometam as relaçóes familiares. Esse resultado demonstra que o contexto familiar é importante para as empreendedoras e influencia as suas atitudes a respeito do crescimento (MARI; POGGESI; DE VITA, 2016).

Vale salientar que apenas uma empreendedora realiza planejamento formalizado. Quanto à autoconfiança para enfrentar o desafio do crescimento, as demais empreendedoras não reuniram todas essas condições simultaneamente. Esse comportamento está estreitamente relacionado à preocupação com o bem-estar familiar. Robb e Watson (2012) afirmam que, assim como optar por correr menos risco ou crescer de forma lenta, buscar o equilíbrio trabalho-família também não é fator determinante para o desempenho de empresas pertencentes a mulheres. Nota-se ainda que, em todos os casos em que inexiste o planejamento formal, a autopercepção das empreendedoras acerca do impacto do crescimento sobre a família é negativa. O Quadro 7 resume os resultados comparativamente com relação às intenções de crescimento.

QUADRO 7

Resumo comparativo dos casos

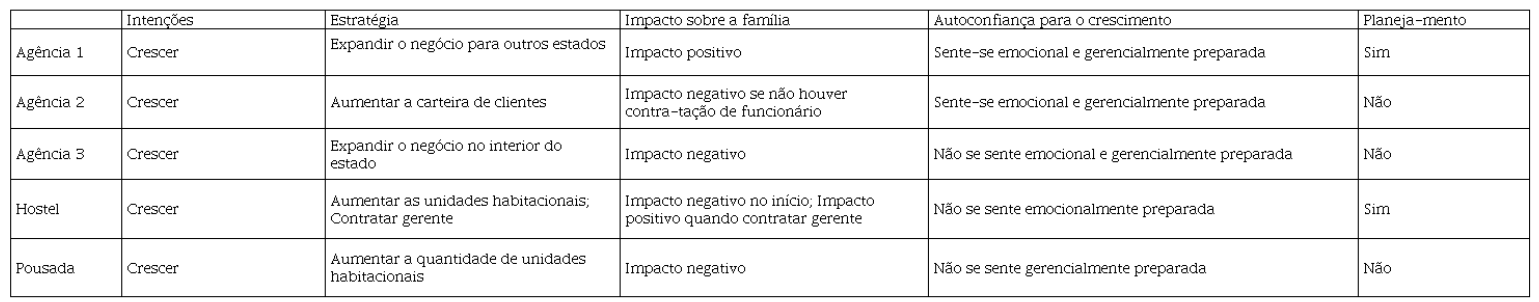

Concluindo essa análise comparativa, verifica-se no Quadro 7 que as empreendedoras deste estudo desejam crescer seu negócio de várias formas: expandindo para outros estados, no mesmo estado ou mesmo crescendo 
a oferta de seus serviços. No entanto, têm percepções distintas com relação ao impacto desse crescimento na vida da família ou sobre a sua confiança com relação a sentir-se emocional e gerencialmente preparada.

\section{CONSIDERAÇÕES FINAIS}

Observou-se que o crescimento do negócio é almejado por todas as empreendedoras, tanto nas agências de viagens como nos negócios de hospitalidade, porém, as formas de promovê-lo são diferentes. Vale destacar que a ausência de estratégias de crescimento nos casos estudados está associada à falta de planejamento que, se existisse, poderia permitir que esse processo ocorresse de forma gradual e com menores riscos, além de impactar positivamente na autoconfiança percebida dessas mulheres. De forma geral, percebe-se, com base nos casos analisados, que a ênfase não é apenas no retorno financeiro, mas em outros fatores, também identificados em outros estudos, como a autonomia, a qualidade de vida, e o equilíbrio entre o negócio e a família.

A preocupação com o impacto negativo do crescimento na família pode ser também destacada como típico de empreendedoras, além do reconhecimento da falta de preparação gerencial. Porém, esses resultados dão indicativos de que a ausência de autoconfiança das empreendedoras parece não influenciar negativamente na intenção de crescimento, pois nenhuma delas assumiu deliberadamente a atitude de manutenção ou redução. Ao contrário, ainda sem reunir os recursos necessários à alavancagem empresarial, pensam em crescer de diferentes formas, e entendem que o crescimento é uma consequência do fornecimento de serviços de qualidade e decisões estratégicas acertadas.

Revelaram-se essas empreendedoras também cautelosas, na medida em que se preocupam em crescer consoante a sua capacidade de administrar os múltiplos papéis e, além disso, a gestão administrativa e financeira. Finalmente, é possível destacar que o crescimento não é visto pelas empreendedoras do estudo como um fim em si mesmo, mas como parte de um processo que acontece naturalmente em negócios que alcançam sucesso.

Pode-se ainda mencionar que estudos sobre essa temática têm contribuído para ampliar o escopo da pesquisa do empreendedorismo na medida em que se contrapõem a teorias econômicas que enaltecem o desempenho e o lucro. Sugerem-se estudos futuros de caráter quantitativo, como os que possam relacionar variáveis, a exemplo das características sociodemográficas das empreendedoras do setor de turismo, a influência da família, a experiência anterior e o estilo de vida, com o impacto que gera no crescimento dos seus negócios.

\section{REFERÊNCIAS}

AHL, H. Why research on women entrepreneurs needs new directions. Entrepreneurship Theory and Practice, v. 30, p. 595-621, 2006.

AHL, E.; MARLOW, S. Exploring the dynamics of gender, feminism and entrepreneurship: advancing debate to escape a dead end? Organization, v. 19, n. 5, p. 543-562, 2012.

ALMEIDA, M. M. A. Influence of gender and financing on tourist company growth. Journal of Business Research, v. 66, n. 5, p. 621-631, 2013.

ALSOS, G. A.; ISAKSEN, E. J.; LJUNGGREN, E. New venture financing and subsequent business growth in men and women-led businesses. Entrepreneurship Theory and Practice, v. 30, p. 669-686, 2006.

ARROYO, M. R.; FUENTES, M. D. M. F.; JIMÉNEZ, J. M. R. Um Estudo Internacional sobre os Fatores que Explicam a Expectativa de Alto Crescimento em Novos Empreendimentos: uma perspectiva de gênero. Revista Brasileira de Gestão de Negócios, v. 18, n. 60, p. 171-190, 2016.

ATELJEVIC, J.; PAGE, S. Introdução. In: ATELJEVIC, J.; PAGE, S. J.; ALMEIDA, M.V. (Org.). Turismo e empreendedorismo. Rio de Janeiro-RJ, p. XII-XVII, 2011. 
BAUGHN, C. C.; CHUA, B. L.; NEUPERT, K. E. The Normative Context for Women's Participation. In: Entrepreneurship: a multicountry study. Entrepreneurship Theory and Practice, v. 30, n. 5, p. 687-708, 2006.

BRUIN, A.; BRUSH, C. G.; WELTER, F. Advancing a framework for coherent research on women's entrepreneurship. Entrepreneurship Theory and Practice, v. 31, p. 323-339, 2007.

CLIFF, J. E. Does one size fit all? Exploring the relationship between attitudes towards growth, gender, and business size. Journal of Business Venturing, v. 13, n. 6, p. 523-542, 1998.

DAVIS, A. E.; SHAVER, K. G. Understanding gendered variations in business growth intentions across the life course. Entrepreneurship Theory and Practice, v. 36, n. 3, p. 495-512, 2012.

EINSENHARDT, K. M. Building theories from case study research. Academy of Management Review, v. 14, n. 4, p. 532-550, 1989.

GATEWOOD, E. J.; SHAVER, K. G.; GARTNER, W. B. A Longitudinal-study of cognitive-factors influencing start-up behaviors and success at venture creation. Journal of Business Venturing, v. 10, n. 5, p. 371-391, 1995.

GEBRAN, M. E.; NASSIF, V. M. J. Como as mulheres aprendem e desenvolvem suas competências empreendedoras? Um estudo exploratório. Encontro Anual da FEA-USP -SemeAd, 16, São Paulo - SP, Anais... USP, SP, 2013.

GEDI - THE GENDER GLOBAL ENTREPRENEURSHIP AND DEVELOPMENT INDEX A 17 - country pilot analysis of the conditions that foster high-potential female entrepreneurship. Disponível em: <https:// thegedi.org/wp-content/uploads/2013/06/Gender-GEDI-Country-Pages> . Acesso em: 7 set. 2016.

GLOBAL ENTREPRENEURSHIP MONITOR. O Empreendedorismo no Brasil. 2016.

GOMES, D. T.; GUERRA, P. V.; VIEIRA, B. N. O Desafio do Empreendedorismo Feminino. ENCONTRO ANUAL DA ANPAD, 35, Rio de Janeiro - RJ, Anais... Rio de Janeiro, RJ, 2011.

GOMES, R. Análise dos dados em pesquisa Qualitativa. In: MINAYO, M. C. de S. Pesquisa Social: teoria, método e criatividade. Petrópolis, RJ: Vozes, 1996. p. 67-80.

HASAN, F. S. M. A.; ALMUBARAK, M. M. S. Factors influencing women entrepreneurs' performance in SMEs. World Journal of Entrepreneurship Management and Sustainable Development, v. 12, n. 2, p. 82-101, 2016.

JENNINGS, J. E.; BRUSH, C. Research on Women Entrepreneurs: challenges to (and From) The Broader Entrepreneurship Literature? Academy of Management Annals, v. 7, n. 1, p. 663-715, 2013.

JONATHAN, E. G. Empreendedorismo feminino no setor tecnológico brasileiro: dificuldades e tendências. ENCONTRO ANUAL DA EGEPE, 3, Brasília, DF. Anais... Anpad, RJ, p. 41-53, 2003.

KAMAU, D. G.; MCLEAN, G. N.; ARDISHVILI, A. Perceptions of business growth by women entrepreneurs. Frontiers of Entrepreneurship Research, Wellesley, MA: Center for Entrepreneurial Studies, Babson College. 1999. Disponível em: <http://www.babson.edu/entrep/fer/papers99/IV/IV_C/IVC\%20Text.html>. Acesso em: 10 ago. 2013.

LI, L. A review of entrepreneurship research published in the hospitality and tourism management journals. Tourism Management, v. 29, n. 5, p. 1013-1022, 2008.

LINDO, M. R. et al. Vida Pessoal e Vida Pessoal: os desafios de equilíbrio para mulheres empreendedoras no Rio de Janeiro. Revista de Administração Contemporânea Eletrônica, v. 1, n. 1, p. 1-15, 2007.

MACHADO, F. B. Dilemas de Mulheres Empreendedoras em Empresas Inovadoras Nascentes. ENCONTRO ANUAL DA ANPAD, 36, Anais... Anpad, RJ, p. 1-16, 2012.

MACHADO, P. H. V. et al. Significados de Sucesso e Fracasso nos Negócios: o que dizem mulheres empreendedoras. ENCONTRO ANUAL DA ANPAD, 32, Anais... Anpad, Rio de Janeiro - RJ, 2008.

MACHADO, P. H. V.; GUEDES, A.; GAZOLA, S. Determinantes e Dificuldades de Crescimento para Mulheres Empreendedoras. RPCA, v. 11, n. 1, p. 85-99, 2017.

MANOLOVA, T. S.; BRUSH, C. G.; EDELMAN, L. F. What do women entrepreneurs want? Strategic Change Journal, v. 17, n. 3-4, p. 69-82, 2008.

MARI, M.; POGGESI, S.; DE VITA, L. Family Embeddedness and Business Performance: evidences from womenowned firms. Management Decision, v. 54, n. 2, p. 476-500, 2016. 
QUENTAL, C.; WETZEL, U. Equilíbrio Trabalho-Vida e Empreendedorismo: a experiência das mulheres brasileiras. ENCONTRO ANUAL DA ANPAD, 26, Salvador - BA, Anais... Rio de Janeiro, RJ, 2002.

ROBB, A. M.; WATSON, J. Gender differences in firm performance: evidence from new ventures in the United States. Journal of Business Venturing, v. 27, n. 5, p. 544-558, 2012.

SERVIÇO BRASILEIRO DE APOIO ÀS MICRO E PEQUENAS EMPRESAS. Anuário das Mulheres Empreendedoras e Trabalhadoras em Micro e Pequenas Empresas - São Paulo: Dieese, 2013.

TAKAHASHI, A. R. W. et al. What now, Joseph? Intrapreneurship, entrepreneurial competences development and work-family conflict in professors of masters and doctorate programs in Management. Tourism \& Management Studies, Special Issue, v. 4, p. 1208-1219, 2013.

TEIXEIRA, R. M. Diagnóstico de Pequenos Negócios Hoteleiros em Sergipe. In: TRIGO, L. G. G. (Ed.). Análises Regionais e Globais do Turismo Brasileiro. São Paulo: Roca, 2005.

TEIXEIRA, R. M.; MORRISON, A. Desenvolvimento de empresários em pequenas empresas de pequeno porte do setor hoteleiro. Revista de Administração Contemporânea, v. 8, n. 1, p. 105-128, 2004.

VASCONCELOS, G. M.; SERAFIM, A. N. F. Embeddedness, Empreendedorismo e Gênero: desafios para tornar forte o sexo frágil. ENCONTRO ANUAL DA ANPAD, 34, Rio de Janeiro-RJ. Anais... Anpad, RJ. p. 1-17, 2010.

VENUGOPAL, V. Investigating Women's Intentions for Entrepreneurial Growth. International Journal of Gender and Entrepreneurship, v. 8, n. 1, p. 2-27, 2016.

WATSON, J. Comparing the performance of male-and female-controlled businesses: relating outputs to inputs. Entrepreneurship Theory and Practice, v. 26, n. 3, p. 91-100, 2002.

WORLD TRAVEL \& TOURISM COUNCIL. Economic Impact of Travel \& Tourism 2016. Annual Update: Summary. Mar. 2016. Disponível em: <http://www.wttc.org/-/media/files/reports/economic\%20impact \%20research/regions\%202016/world2016.pdf>. Acesso em: 7 set. 2016.

YIN, R. K. Estudo de Caso: planejamento e métodos. Bookman, Porto Alegre, 2015.

ZAMPETAKIS, L. A. et al. Sex differences in entrepreneurs' business growth intentions: an identity approach. Journal of Innovation and Entrepreneurship, v. 5, n. 1, p. 29, 2016. 